DARK, J., DARK, K. A.\& ZUCKER, I. (1987) Long day lengths increase brain weight and DNA content in the meadow vole, Microtus pennsylvanicus. Brain Research, 409, 302-307.

HORTON, T. H. \& STETSON, M. H. (1990) Maternal programming of the foetal brain dictates the response of juvenile Siberian hamsters to photoperiod. Journal of Experimental Zoological Supplement, 4, 200-202.

LEE, T. M. et al (1988) Vole infant development is influenced perinatally by maternal photoperiodic history. Americn Journal of Physiology. 255, 831-838.

Charing Cross and Westminster Medical School

D. J. QUESTED Department of Neurophysiology

The Priory Hospital

Priory Lane, Roehampton

London SW15 5JJ

SIR: I read with interest the paper by Kendell \& Adams (Journal, June 1991, 158, 758-763) showing that the lower the temperature in the Autumn, the higher the incidence of schizophrenia the following Spring. The authors point out that the effect is a small one, and that some infective or nutritional influence may be the actual aetiological agent. However, the World Health Organization's studies on schizophrenia demonstrated that the incidence of schizophrenia as 'broadly' defined showed an approximate three-fold variation from country to country (Sartorius $e t$ al, 1986) and also that the outcome of schizophrenia was significantly better in 'developing' countries than in the 'developed' world. Some time ago I carried out analyses using incidence and outcome measures from the WHO investigations, and found large and signifcant correlations between these and indices of environmental temperature (Gupta \& Murray, 1991b). Furthermore, when taken together with other data (for example, from biological studies, e.g. McDonald \& Param, 1985), such epidemiological findings suggest that the link between environmental temperature and schizophrenia may have aetiological significance (Gupta, 1990).

In the same issue (Journal, June 1991, 158, 834 835), Eagles makes some interesting observations about the paper entitled "Is schizophrenia disappearing?" of which I was a co-author. He points out that first-admission rates were not age standardised, but also notes that in patients aged under 55 , a fall was apparent in all age groups. This he argues is evidence against a purely perinatal explanation of the apparent decline in incidence of the disease, and he suggests that reduced rates of infectious illnesses may also be involved. However, as pointed out elsewhere (Gupta \& Murray, 1991a), if increased resistance to infections is due in part to improved health care early in life (for example due to immunisation programmes), then once again one would have expected a selective fall in the incidence of schizophrenia among younger patients. The effects of any additional triggering factor are likely, on the other hand, to be dependent on influences operating in a period comparatively close to the time of illness onset. Furthermore, if the analysis of the data from England and Wales is correct, the intensity of this factor probably started to change sometime in the 1960 s.

GuPTA, S. (1990) Cross-national differences in the incidence and outcome of schizophrenia. Paper presented to the Autumn Quarterly meeting in the Royal College of Psychiatrists, London, October, 1990. Abstract published as part of a supplement to Psychiatric Bulletin.

- \& MURRAY, R. M. (1991a). The changing incidence of schizophrenia: fact or artefact? Directions in Psychiatry, 11, 1-8.

\& $\&$ - $(1991 b)$ The relationship of environmental temperature to the incidence and outcome of schizophrenia. British Journal of Psychiatry (in press).

McDonald, C. \& Param, C. (1985) Body temperature in psychiatric disorders. Biological Psychiatry, 20, 817.

SArtorius, N., JABLENSKY, A., Korten, A. et al (1986) Early manifestations and first contact incidence of schizophrenia in different cultures. A preliminary report on the initial evaluation phase of the WHO Collaborative Study on Determinants of Outcome of Severe Mental Disorders. Psychological Medicine, 16, 909-928.

Institute of Psychiatry

Sunjai GuPTA

London SE5 8AF

\section{Ethnic nomenclature}

SIR: I remain perplexed by the continuing Journal use of the term 'Caucasian' to describe people of White European origin. This supposedly scientific designation has no rigorous meaning: it was originally popularised by the biologist Johann Blumenbach (1795) when he attempted to modify Linnaeus' definition of a species so as to catalogue different human groups. Blumenbach chose 'Caucasian' to designate the 'first race' (from which all others were held to be degenerate forms) because we all split up after Noah's Ark landed on Mount Ararat in the Southern Caucasus (Genesis 9: 18-19). The term continued in use during the 19th century, variously including the Semitic-speaking peoples (Jews, Arabs) or excluding them. It consistently included the Indo-European speaking peoples of South Asia: the societies referred to in the Journal as 'Asian' where they are counterposed to 'Caucasians'. Contemporary biological anthropology and population genetics find no value in this confusing notion of 'race' which elides the cultural and the biological. Instead, they prefer to use the deliberately ambiguous term 'ethnic group' in which a group of people are referred to by the term they themselves use: hence Inuit, not Eskimo. 